\title{
Consejos y comités editoriales de las revistas médicas
}

\author{
Francisco Espinosa-Larrañaga, Miguel Cruz-López, Martha Eugenia Rodríguez-Pérez y \\ Alejandro Treviño-Becerra \\ Academia Nacional de Medicina de México, Gaceta Médica de México, Ciudad de México, México
}

Las publicaciones médicas periódicas, conocidas coloquialmente como revistas médicas, son editadas en instituciones de salud (Revista Médica del Instituto Mexicano del Seguro Social), instituciones educativas (Revista de la Facultad de Medicina de la Universidad Nacional Autónoma de México) o academias y asociaciones civiles médico-científicas (Gaceta Médica de México). En las revistas médicas participan diversos grupos de profesionales con actividades y objetivos específicos, todos ellos con la finalidad de publicar una revista médica con calidad científica y editorial. Este conjunto de expertos académicos y científicos son los consejos editorial y de administración, los comités editoriales (nacionales e internacionales), los revisores pares, los editores y, finalmente, quienes participan en el proceso de edición e impresión.

Entre la comunidad médico-científica se conoce cuál es el papel de los editores y de quienes cuidan la edición que finaliza con la impresión o publicación electrónica. También se conoce e identifica la valiosa actividad que tiene el grupo de revisores pares. Por el contrario, poco se sabe acerca de cuál es la participación de los miembros del consejo editorial, cómo y por quién son designados, qué perfil profesional y académico deben cumplir. Lo mismo ocurre respecto a los miembros del comité editorial, quienes con frecuencia son confundidos con los revisores. Una realidad es que los miembros del consejo y los comités sobresalen en aspectos científicos y académicos en el ámbito de la medicina.

El consejo de administración desempeña un papel relevante, si bien en la mayoría de las revistas médicas mexicanas no lo tienen en consideración en la página de créditos en su página legal. Su participación es considerada obvia por muchos y por otros como una colaboración inherente a la labor que desarrolla en una institución pública o asociación civil. En la mayoría de las ocasiones participa por circunstancias de temporalidad y ubicación.

Nuestro propósito es compartir conceptos y experiencias con los lectores que les permitan conocer las funciones, perfil y mecanismo para formar parte de un consejo o comité editorial. Acerca de los editores y sus funciones se conocen más y ha sido motivo de otra comunicación.

\section{El consejo editorial}

El consejo editorial es la autoridad encargada de definir los principios editoriales generales académicos y éticos que buscan dar respuesta a las siguientes interrogantes: ¿cuál es el propósito de la publicación?, ¿a qué tipo de lector está dirigida la revista?, ¿cuál es el campo temático y extensión que debe tener?, ¿cuál será su periodicidad y extensión en número de páginas?, ¿cómo contar con un procedimiento estandarizado de evaluación? Una de las actividades que debe realizar es proponer lineamientos para su integración, organización y funciones.

En Gaceta Médica de México, el consejo editorial está integrado actualmente por los últimos expresidentes de la Academia Nacional de Medicina de México. Dado que la duración en la presidencia es de dos años, cada dos años se incorpora un nuevo miembro del consejo y sale el más antiguo. En cuanto a su organización, funciona como un órgano colegiado. Entre las tareas que realiza se encuentran las siguientes:

1. Generar y actualizar periódicamente los lineamientos que rigen al propio consejo.
Fecha de recepción: 27-02-2019

Fecha de aceptación: 28-02-2019

DOI: 10.24875/GMM.19005110
Gac Med Mex. 2019;155:121-123

Disponible en PubMed www.gacetamedicademexico.com 
2. Realizar reuniones periódicamente.

3. Establecer un sistema de evaluación del cumplimiento de los principios editoriales y éticos establecidos por el propio consejo y el desempeño de los editores, así como los estándares de producción editorial para la empresa editora-impresora con la que se colabora.

4. Asesorar en la elaboración de contratos con empresas editoriales-imprentas.

5. Proponer mecanismos de selección, integración, funciones y tiempo de permanencia del comité editorial a los editores.

6. Convocar y coordinar las reuniones de comité editorial y editores encaminadas a la toma de decisiones, establecimiento de estrategias y evaluación de la publicación.

\section{Comité editorial}

Existen revistas médicas locales o regionales, nacionales e internacionales. Las primeras integran un comité editorial nacional y las últimas, uno internacional. Se define al comité editorial como un grupo académico que representa a la publicación dentro de su campo de influencia ya sea institucional, especialidad o área de investigación o ámbito geográfico. Su propuesta, selección e integración de sus miembros, así como duración y funciones deben partir del consejo editorial o de los editores. Los integrantes de este comité podrán ser o no ser miembros de la Academia y durarán en el cargo por cuatro años y su nombramiento podrá ser renovado. Aunque no es su principal actividad, pueden participar como revisores pares en el campo científico de su dominio. Entre sus funciones se encuentran:

1. Representar con dignidad y profesionalismo a la publicación.

2. Participar en las reuniones convocadas por el consejo editorial o los editores.

3. Dar a conocer y promover en su ámbito de influencia a la revistas médicas que representan.

4. Favorecer el envío de trabajos a las revistas que representan para su publicación.

5. Asesorar a los autores acerca del envío, instrucciones para autores y proceso de arbitraje.

6. Propiciar la consulta en línea de la revistas médicas ofreciendo la dirección electrónica o liga de los sitios mencionados.

7. Proponer acciones de mejora a la calidad de la publicación al consejo editorial y a los editores.

\section{Consejo o grupo de administración}

Se define como el responsable de obtener y proporcionar los recursos humanos, de financiamiento y materiales que requieren las revistas médicas para el logro de sus objetivos. En las instituciones públicas de salud o educativas depende de un departamento u oficina de publicaciones. Por ejemplo, en el caso de las asociaciones médicas o científicas, entre las que se encuentra la Academia Nacional de Medicina de México, la mesa directiva es la garante de la contratación de recursos humanos, obtención de los recursos financieros que permitirán el procesamiento e impresión de la publicación y la compra de recursos materiales para la operación cotidiana de las publicaciones. Su participación queda resaltada, pero enmascarada, al mencionar a la mesa directiva que dirige la asociación médica en la página legal de la revista. Sus funciones son las siguientes:

1. Solicitar a los editores las necesidades de recursos para cumplir con las publicaciones.

2. Realizar un plan o estrategia para la obtención de los recursos necesarios para la revistas médicas.

3. Solicitar cotizaciones a proveedores de servicios o materiales.

4. Analizar y elegir la mejor opción y, en caso necesario, con apoyo del consejo editorial y editores como asesores técnicos.

5. En caso de requerirse, como consecuencia de la obtención de fondos financieros, realizar informes y agregar evidencias físicas y contables solicitadas por el donante de recursos.

6. Evaluar que los recursos financieros otorgados hayan cumplido con su objetivo con eficiencia y transparencia, pero, sobre todo, con probidad.

Muchas instituciones de salud, educativas y civiles desarrollan revistas médicas. La página legal nos permite conocer su estructura. Esperamos que este documento haya aclarado y precisado lo que son los consejos de administración y editorial, el comité editorial y los revisores pares. Uno de los indicadores que los comités evalúan en las revistas médicas para su incorporación a las base de datos es la integración de sus consejos y comités editoriales. En México, la institución que tiene mejor descrita la integración, funciones y permanencia de los consejos y comités editoriales es la Universidad Nacional Autónoma de México, ejemplo de ellos son los reglamentos del comité editorial de la Facultad de 
Medicina y del Instituto de Investigaciones Estéticas, en los cuales se puede observar su organización, integración, funciones y tiempo de permanencia de sus integrantes.

Consideramos que los editores y responsables de las revistas médicas debemos trabajar al respecto, lo cual tendría como beneficio reconocer la participación de los diferentes grupos involucrados en la edición, así como su funcionamiento e integración con responsabilidad para generar recursos, su transparencia en el uso de los mismos y, sobre todo, convertirlas en publicaciones incluyentes de todos los participantes como consejos y comités.

\section{Lecturas recomendadas}

1. Miyahira-Arakaki JM. Criterios de calidad de las revistas científicas. Rev Med Herediana. 2008;19(1):1-4.

2. Academia Nacional de Medicina de México. Estatuto. Academia Nacional de Medicina de México, A. C. Capitulo XI. México, ANMM; 2013. p. 36.

3. Reglamento del comité editorial de la Facultad de Medicina, Facultad de Medicina, Universidad Nacional Autónoma de México. Mecanograma. p. 4-14.

4. Reglamento del Comité Editorial. Instituto de Investigaciones estéticas. Universidad Nacional Autónoma de México. Mecanograma 31 de octubre de 2011. p. 5-24. 